JOURNAL OF GEOPHYSICAL RESEARCH, VOL. 89, NO. B9, PAGES 7697-7707, SEPTEMBER 10, 1984

\title{
FOCAL MECHANISMS AND AFTERSHOCK LOCATIONS OF THE SONGPAN EARTHQUAKES OF AUGUST 1976 IN SICHUAN, CHINA
}

\author{
Lucile M. Jones,,$^{1,2}$ Weibin Han,3 Egill Hauksson,,$^{1,4}$ Anshu Jin, ${ }^{5}$
} Yaoguo Zhang, ${ }^{3}$ and Zhuoli Luo ${ }^{3}$

\begin{abstract}
The precursory swarm, three mainshocks ( $M=7.2,6.7,7.2)$, and aftershocks of the Songpan earthquakes have been reanalyzed using both local and teleseismic data. The three mainshocks of this sequence occurred on the Huya fault over a 7-day perlod. Relocations of the aftershocks using local arrival times show that three fault strands were activated during this sequence. Each malnshock occurred on a separate strand, each one south of the strand activated in the previous malnshock, and the aftershock zones of each mainshock appear to abut rather than overlap. Fault plane solutions determined by matching teleseismic $P$ waveforms at World-Wide Standard Selsmograph Network stations with synthetic seismograms are consistent with the observed aftershock zones, The first and third mainshocks $\left(M_{0}=1.3 \times 10^{19}\right.$ and $8.4 \times 10^{18} \mathrm{~N} \mathrm{~m}$, respective1y) showed almost identical senses of motion, a combination of reverse and left-lateral strike-slip motion, on parallel strands, striking $\mathrm{N} 15^{\circ} \mathrm{W}$, that were separated by a large rightstepping en echelon offset. The second mainshock $\left(M_{0}=4.0 \times 10^{18} \mathrm{~N} \mathrm{~m}\right)$, occurred in this of fset on a fault at a steep angle $\left(\sim 125^{\circ}\right)$ to the other two strands and showed almost pure reverse motion. Differences in the orientations of the slip vectors of the three mainshocks show that the first mainshock increased the normal and shear stresses on the fault segment that moved in the second mainshock and that the second mainshock decreased the normal stress on the fault segment activated by the third malnshock. These changes in normal stresses may have given rise to the longer time between the first and second events ( 5 days) as compared with the time between the second and third events ( 30 hours). A precursory swarm that preceded the Songpan sequence by 3 years occurred in a volume that surrounded the northernmost part of the planar aftershock zone. The time between the start of the swarm and the mainshocks and the magnitude of the largest event in the swarm are similar to those seen for precursory swarms in Soviet Central Asia.
\end{abstract}

\footnotetext{
${ }^{1}$ Lamont-Doherty Geological Observatory of Columbia University, Palisades, New York.

${ }^{2}$ Now at U.S. Geological Survey, Seismologica1 Laboratory, California Institute of Technology, Pasadena.

${ }^{3}$ Sichuan Provincial Selsmology Bureau, Chengdu, Sichuan, People's Republic of China.

${ }^{4}$ Now at Department of Geological Sciences, University of Southern California, Los Angeles.

${ }^{5}$ Institute of Geophysics, State Seismology Bureau, Beijing, People's Republic of China.
}

Introduction

The Songpan earthquake sequence that occurred on the Huya fault in northwestern Sichuan Province, People's Republic of China, in August 1976 consisted of a precursory swarm, three mainshocks ( $M=7.2,6.7$, and 7.2 ), and a large sequence of aftershocks. A medium-term prediction that an earthquake was likely in the Songpan region within a year was issued in November 1975, based in part on the occurrence of the precursory swarm. The Songpan sequence and associated precursory data have been described by several investigators [e.g., Wallace and Teng, 1980; Sichuan Provincial Seismology Bureau, 1979; Han and Xia, 1980; Jennings, 1980]. This report presents a reanalysis of both local and teleseismic data on the selsmicity associated with the sequence.

Triplets of earthquakes like the Songpan earthquakes which occur on the same fault with several days between the mainshocks are relatively rare. Large or great earthquakes, however, are often modeled as consisting of several subevents that occur within seconds of each other. There has recently been considerable interest in complex multiple events and speculation on what role the geometry of faults plays in determining the style of rupture [e.g., Mog1, 1969; Rial, 1978; Kanamort and Stewart, 1978; Das and Scholz, 1981; Ak1, 1979; Fukao and Furumoto, 1975]. However, because the subevents in a multiple rupture occur within seconds of each other, it is often difficult to separate the source parameters of each subevent. If the Songpan triplet can be interpreted as three subevents separated by days Instead of seconds, the temporal separation of the events provides a unique opportunity to see the detalls of rupture on a complex fault. We have therefore relocated the aftershocks of the Songpan sequence and determined the fault plane solutions by waveform modeling to resolve the mechantcal relationships between the three mainshocks. We have examined how the geometry of the fault affected the distribution in space and time of the seismicity.

The Songpan earthquakes were preceded by an earthquake swarm that lasted for 3 years at the northern end of the aftershock zone of the first mainshock. It has been suggested that swarms may be long-term seismic precursors to large earthquakes [e.g., Evison, 1977a, b; Kristy and Simpson 1980; Johnson and Hi11, 1983]. It 1 s important, in testing this hypothesis, to determine the physical relationship between a swarm and a large earthquake that occur in the same place. We have thus relocated the events in the swarm to examine this relationship.

\section{Geologic Setting}

The sequence occurred in the mountains that form the eastern edge of the Tibetan plateau 


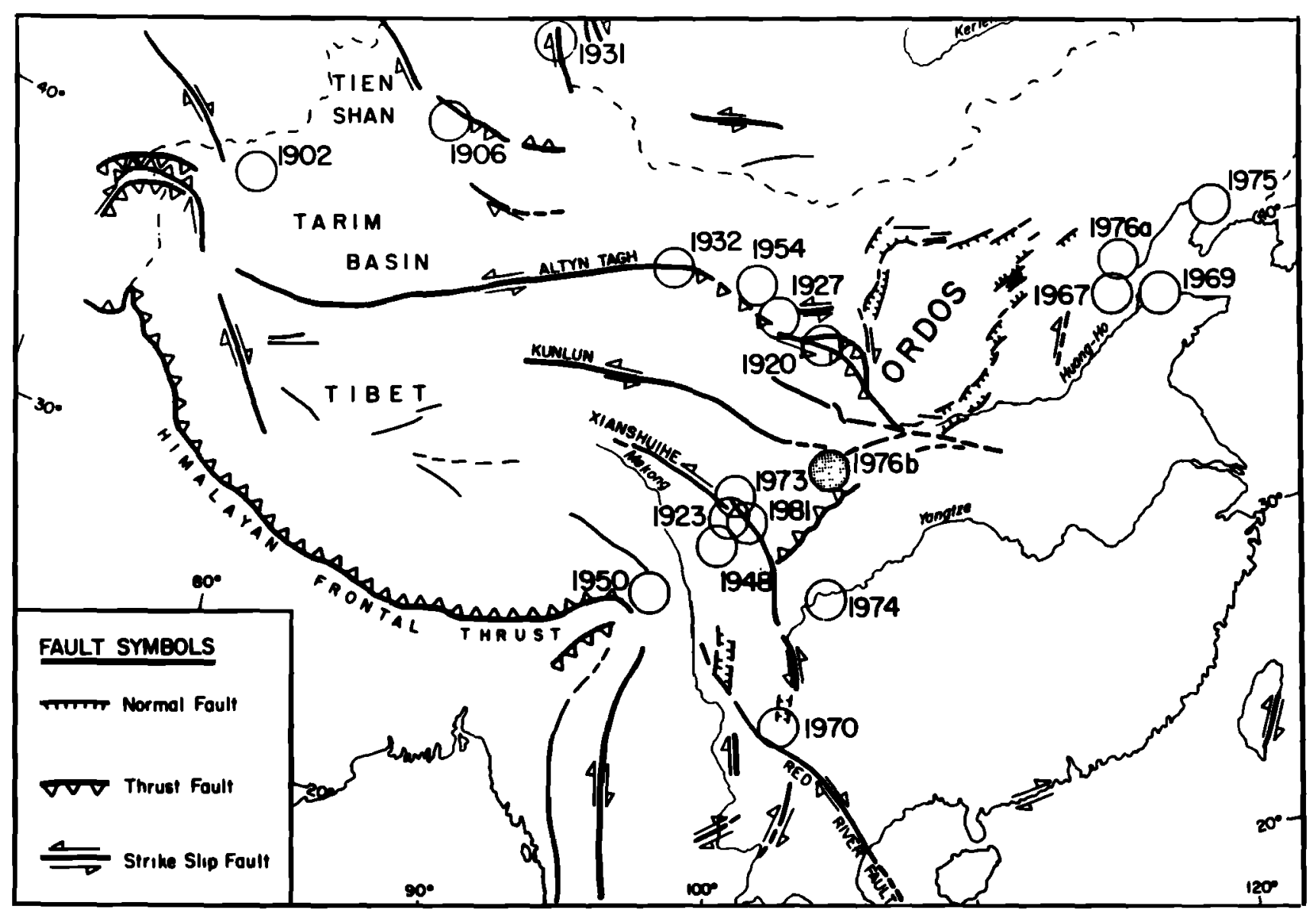

Fig. 1. A map of China showing major faults, selected major earthquakes of the last 80 years, and the location of the Songpan earthquake sequence (shaded clrcle) (from Wesnousky et al., 1984).

(Figure 1). Four major faults control the tectonics of the region. These are the Xlanshuihe fault (also called the Kanting fault [Tapponier and Molnar, 1977]), the Kunlun and Altyn Tagh faults, all left-lateral strike-slip faults, and the Longmenshan thrust fault. The three strike-slip faults are interpreted as moving Tibet and western China eastward to accommodate the movement of India into the Asian continent [Tapponier and Molnar, 1977; Han and $\mathrm{Xia}, 1980]$. The crustal shortening associated with the Longmenshan thrust is accommodating some of this eastward motion. The large topographic relief across the Longmenshan demonstrates that significant crustal shortening has taken place. The sequence actually occurred on the Huya fault, a short $(\sim 80 \mathrm{~km})$ fault lying between the XIanshuihe, Kunlun, and Longmenshan faults. This fault has not been mapped in detail because of the difficult terrain, but no geological evidence of significant of $f$ set has been reported on $1 t$.

While the Longmenshan fault appears to have accommodated significant crustal shortening in the Quaternary, the record of historical seismicity shows that it has been relatively aseismic in the last 2000 years [Sichuan Provinclal Seismology Bureau, 1980; Han and X1a, 1980]. No earthquake of $M \geq 7.0$ has been recorded on the Longmenshan, and no significant activity ( $M \geq$ 5.0) has been recorded on the Longmenshan north of its intersection with the Huya fault in that time (Figure 2). In contrast, the Huya fault system has experienced three events of $M \geq 7.0$ and numerous earthquakes of $M>6.0$ in the last hundred years. On the basis of these different levels of activity, Han and Xia [1980] suggest that the Huya fault can be interpreted as a recent extension of the Kunlun fault. If the Kunlun fault were to extend parallel to the Xianshuthe fault, it would pass through the epicenters of the Songpan earthquakes and intersect the Longmenshan fault at the boundary between the regions of different levels of seismic activity.

\section{Aftershocks}

Data

Over 400 aftershocks of $M>3.0$ were recorded by the selsmograph network of the Sichuan Provincial Selsmology Bureau from August 16 to August 31, 1976. The temporal distribution of these events is shown in Figure 3. Chinese seismologists determined preliminary epicenters from S-P times and calculated local magnitudes. Two hundred of these events were chosen for relocation in this study. All of the events with $M \geq 3.3$ were relocated as we11 as all events of $M$ $=\overline{3} .0-3.2$ which occurred within 24 hours of any 
of the mainshocks. A simple Geiger inversion location program on an HP-85 microcomputer was used to check the consistency of the read arrival times in Sichuan. The final locations of the events were determined using the HYPOINVERSE location program [Klein, 1978].

$P$ wave arrival times from 12 to 16 stations and $S$ wave arrival times from 4 to 12 stations were used to locate most of the earthquakes; four of the stations had three-component instruments (Figure 2). The arrival times of both $P$ and $S$ waves at the three closest stations $(1,2$, and 3 in Figure 2) were reread from the original seismograms with an accuracy of about $0.1 \mathrm{~s}$. For the more distant stations, both previously read arrival times and reread arrival times were used. All inconsistent arrival times were rechecked by rereading the original seismograms. Seismograms from seismic stations located in Gansu province (stations 4, 5, 16, and 17 in Figure 2) were not available, but $P$ and $S$ wave arrival times from the four Gansu stations that are closest to Sichuan were taken from published bulletins. If these arrival times were inconsistent with the readings from the stations in Sichuan Province, they were either given low weights or removed from the data set.

Since the seismograms were recorded locally using a different clock at each station as a time standard, clock correction values that were taken manually with a stop watch every 12 hours with respect to Befjing standard time had to be applied to correct the observed arrival times. clock corrections from an 8-week period bracketing the mainshocks were plotted together for each station (including those in Gansu) to obtain a best estimate of an appropriate clock correction value. Hence in most cases an average relative timing accuracy of approximately $0.1-0.2$ was obtained. In the cases where irregular clock drift or unclear minute marks made the timing accuracy less reliable the arrival times were assigned lower weights than the high quality arrivals. These precautions have been shown to improve significantly the quality of the locations determined from readings with this type of clock correction [Jones et al., 1982].

The velocity structure of the crust and upper mantle in Sichuan Province is not well known. Traditionally, local seismologists have used a simple model that consists of a $40-\mathrm{km}-\mathrm{thick}$ layer with a velocity of $6.0 \mathrm{~km} / \mathrm{s}$ over a half space with a velocity of $8.05 \mathrm{~km} / \mathrm{s}$. To select an appropriate veloctty model, a set of 10 earthquakes was located using several different velocity models. A layer velocity of $5.57 \mathrm{~km} / \mathrm{s}$ of $40 \mathrm{~km}$ thickness with a half-space velocity of $7.9 \mathrm{~km} / \mathrm{s}$ was found to give the least number of earthquakes with zero or negative depths or located below $20 \mathrm{~km}$ (the average maximum depth of brittle-elastic faulting in China [Molnar and Deng, 1984]). To compensate for consistently early arrivals of both $P$ and $S$ waves at the more distant stations, a two-layer model over a half space was chosen. This model consists of an upper layer thickness of $25 \mathrm{~km}$ with a velocity of $5.57 \mathrm{~km} / \mathrm{s}$, a lower layer with a thickness of 15 $\mathrm{km}$ and a velocity of $6.3 \mathrm{~km} / \mathrm{s}$, and a half space with a velocity of $7.9 \mathrm{~km} / \mathrm{s}$. This boundary between the two layers at $25 \mathrm{~km}$ depth is probably not a sharp boundary, and the model may just be

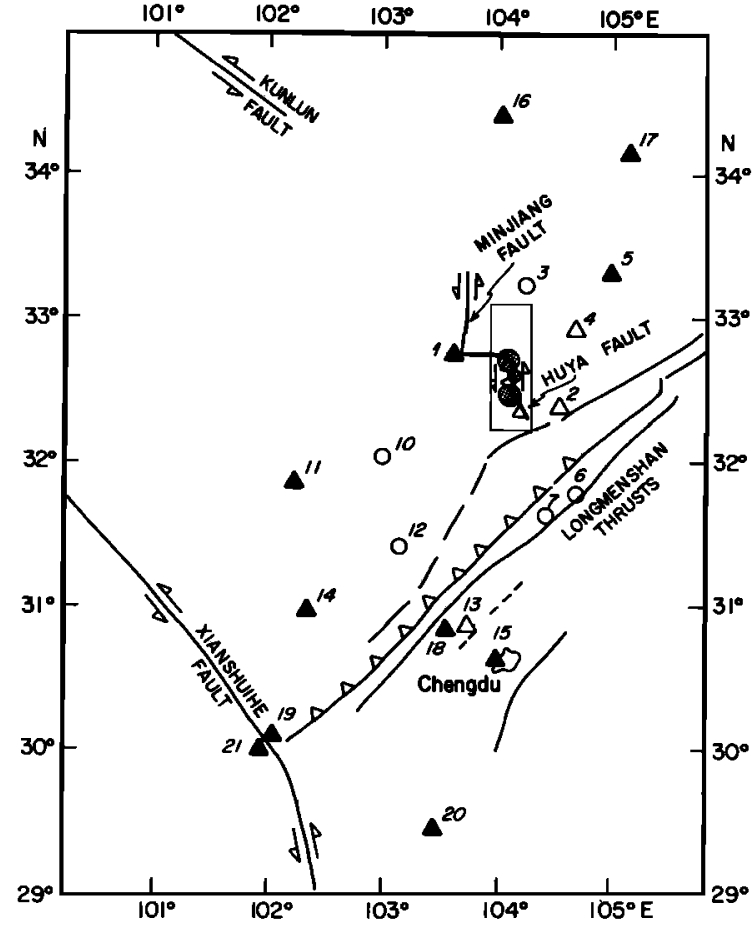

Fig. 2. Map of the Songpan region showling the three mainshocks of the 1976 sequence (shaded circles). The rectangle surrounds the area shown in Fig. 4. The major faults of the area are shown along with the seismic stations used in the aftershock relocations. The triangles are threecomponent stations (solid, operating since 1973, and open, operating since the summer of 1974). The open circles are temporary one-cotnponent stations installed just before the mainshocks. Stations in Gansu Province for which seismograms were not avallable for rereading are $4,5,16$, and 17.

reflecting the gradual increase of velocity with depth. A Poisson's ratio of 1.64 was determined as an average value from numerous Wadati diagrams of the arrival time data. The reason for this low value is not clear, but $1 t$ is consistent with arrivals of events in the region for the last 10 years [Sichuan Provincial Seismology Bureau, $1979]$.

Th1s model agrees with the $S$ wave velocity structure determined by Feng and Teng [1983] for this region. In that study, surface waves were used to determine $S$ wave velocities for all of central and eastern Asia. The Songpan earthquakes lie at the western edge of region 47 of that study, for which a two-layer model was determined. The $S$ wave velocities determined were $3.24-3.45 \mathrm{~km} / \mathrm{s}$ for the first layer and 3.87 $\mathrm{km} / \mathrm{s}$ for the second, which agree well with the values we use when the low Polsson's ratio of the region is taken into account. The thickness of the whole crust and the mantle velocity were taken from that study as $45 \mathrm{~km}$ and $7.9 \mathrm{~km} / \mathrm{s} \mathrm{re}-$ spectively.

The four closest stations are located $40-50 \mathrm{~km}$ away from the epicentral regton. The largest azimuthal gap is equal to or less than $90^{\circ}$. Hence this network of 16 stations that was used to locate the aftershocks is well sulted to 


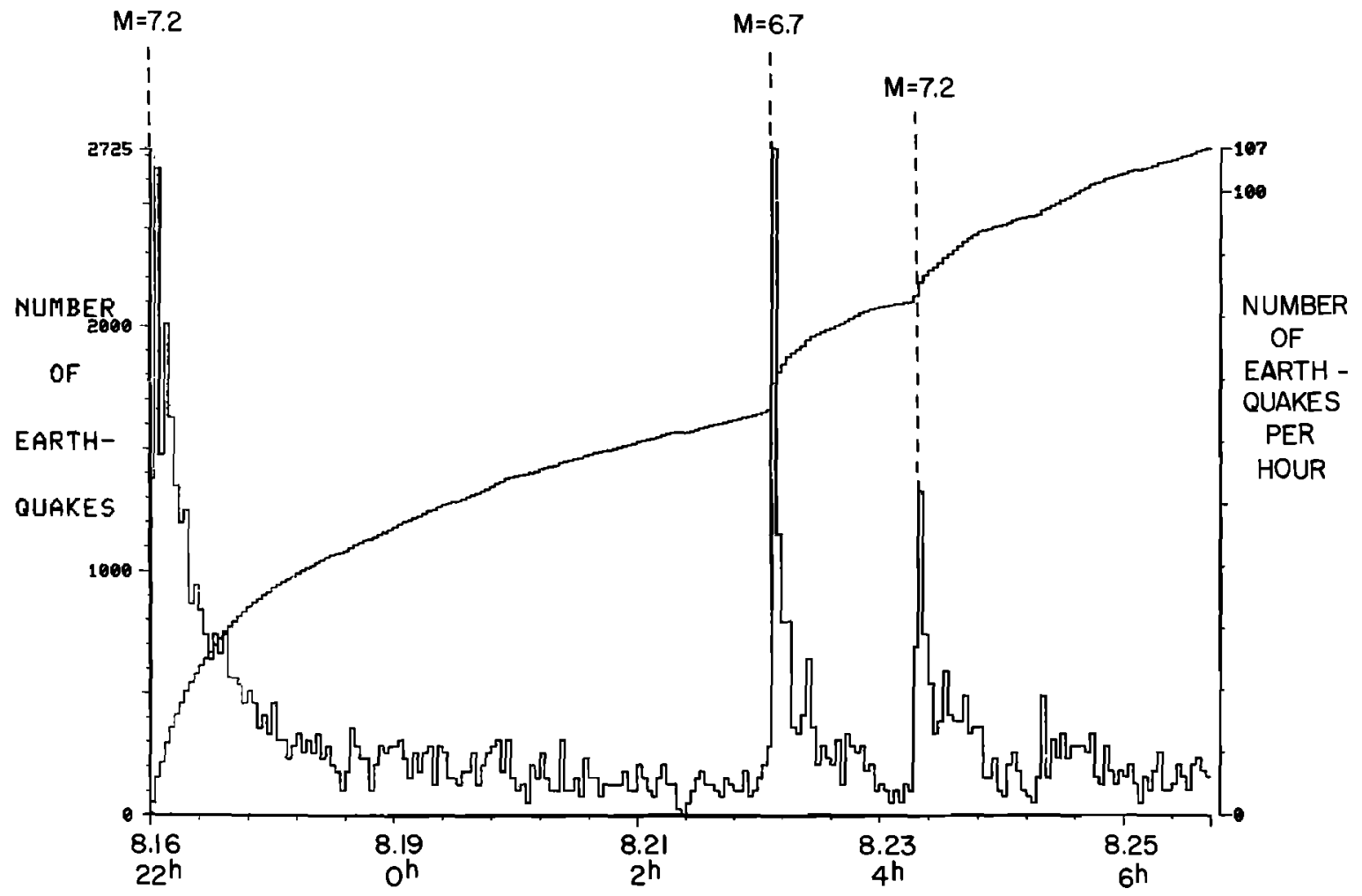

Fig. 3. The temporal distribution of the Songpan aftershock sequence. The number of events of $M \geq 2.0$ that occurred in each hour are shown.

provide high-quality epicentral locations. The average relative horizontal error in our locations was about $2 \mathrm{~km}$, and the average Rms was $0.4 \mathrm{~s}$. Those events with an Rms value greater that $1 \mathrm{~s}$ (about $5 \%$ of the events) were not used. Because of the uncertaintles in the velocity structure and the distance to the nearest station, the hypocenters of the earthquakes are not as well constrained. However, the large number of $S$ readings used in the analysis have decreased the errors of the relative depth to a few kflometers. The absolute depths, however, are dependent on the velocity model used.

\section{Results}

The Songpan mainshocks are characterized by relatively short and almost vertical aftershock zones. All three malnshocks occurred along the Huya failt and have abutting aftershock zones that extend down to depths of $15-20 \mathrm{~km}$ and have a total length of $80 \mathrm{~km}$. The source parameters of the three mainshocks are listed in Table 1.

The temporal development of the aftershock zone is shown in Figure 4. No inmediate foreshocks preceded the first mainshock which occurred at 2206 (al1 times are Beijing time) on Aingust 16, 1976. The epicenter of the first mainshock is located near the northern end of the geologically mapped section of the Huya fault. The initial aftershock zone, which developed during the first 3 hours, reveals a narrow band of seismicity extending for $30 \mathrm{~km}$ subparallel to the Huya fault with concentrations of activity at each end of the zone (Figure 4a). The spatial distribution of the aftershocks with respect to the epicenter of the mainshock is consistent with bilateral rupture. The strike of the aftershock zone is $10^{\circ}-15^{\circ}$ west of north. The relatively low level of aftershock activity near the hypocenter of the mainshock could be an artifact of the data set. Several of the large earthquakes that occurred immedlately following the mainshock could not be located because the time marks on the records were lost in the coda of the mainshock.

After these first 3 hours but before the second mainshock occurred (Figure 4b), the northern end of the aftershock zone gradually extended about $10 \mathrm{~km}$ farther north at a slight angle to the rest of the aftershock zone. No large (M> 4.5) aftershock occurred in this northern section. The cluster of aftershocks at the southern end of the zone showed continued aftershock activity. The second mainshock occurred at the edge of this cluster. No increase in the rate of aftershocks could be seen before the second mainshock.

The second mainshock occurred 5 days after the first event, at 0549, August 22, 1976, at the southern end of the first aftershock zone (Figure 4c). It appears to have its own aftershock zone extending about $12 \mathrm{~km}$ and striking east of north, thus at a steep angle $\left(\sim 125^{\circ}\right)$ to the aftershock zones of the other two mainshocks. Within the resolution of our data the aftershock zones of the first and second mainshocks abut rather than overlap. A change in strike in the Huya fault coincides with the location of the second aftershock zone. The orientation of the second aftershock zone suggests that the second mainshock may have had a unilateral-type rupture, 

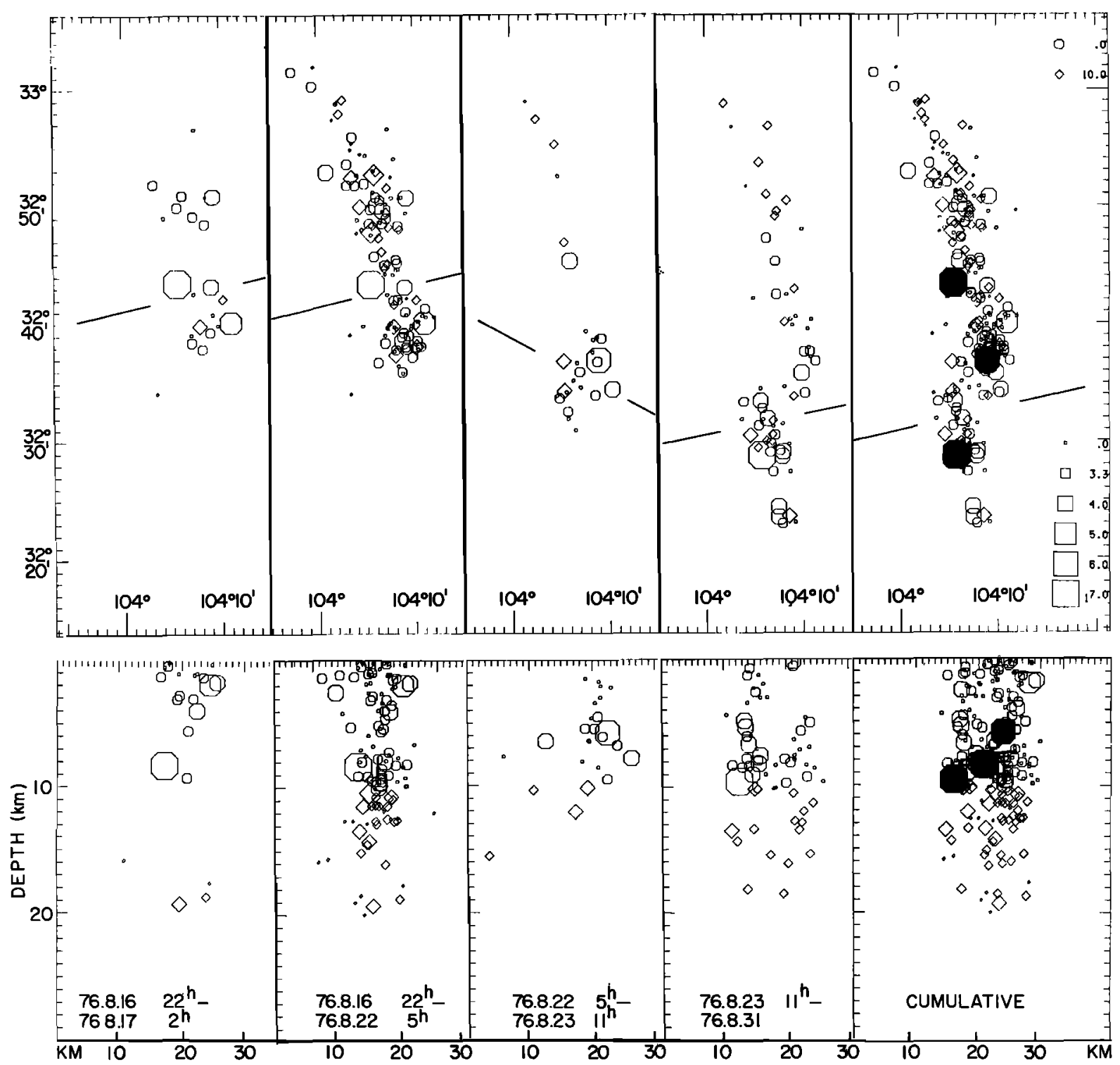

Fig. 4. The epicenters of the Songpan aftershocks located in this study. Octagons are events with a depth less than $10 \mathrm{~km}$, and diamonds are events deeper than $10 \mathrm{~km}$. The size of the symbol varies with magnitude. The earthquakes are plotted separately by time, (a) The first 3 hours of the sequence, (b) All events from the first mainshock until just before the second mainshock, (c) All events from the second malnshock until just before the third, (d) All events from the third mainshock until the end of August, (e) All events in the sequence. Below each map is a plot of the depths of the events projected along the line shown in each figure.

although this cannot be completely resolved.

The third mainshock occurred 30 hours after the second, at 1133, August 23, 1976, and ruptured a segment of the Huya fault south of the second aftershock zone (Figure 4d). The third aftershock zone is similar to the first zone with a strike of approximately $N 15^{\circ} \mathrm{W}$, although its total length is somewhat smaller $(20-25 \mathrm{~km})$. The third malnghock is not located at the end of the second aftershock zone but rather $15 \mathrm{~km}$ south of the zone. Its rupture zone appears to be bilateral and abuts with the southern end of the second aftershock zone.

Seen overall (Figure 4e), the aftershock zones of these earthquakes show a fault with two parallel en echelon segments (the aftershock zones df the first and third events). These segments are separated by a large right-stepping offset through which another fault has extended on which the second mainshock occurred.

The computed depths of the aftershocks are also shown in Figure 4. Although the relative errors in the depths $(+5 \mathrm{~km})$ are much larger than those in the epicentral locations $(+2 \mathrm{~km})$, some general features of the depth distribution can still be resolved. Most noteworthy is that the aftershocks of the second event are shallower than those of the first and third events. The 


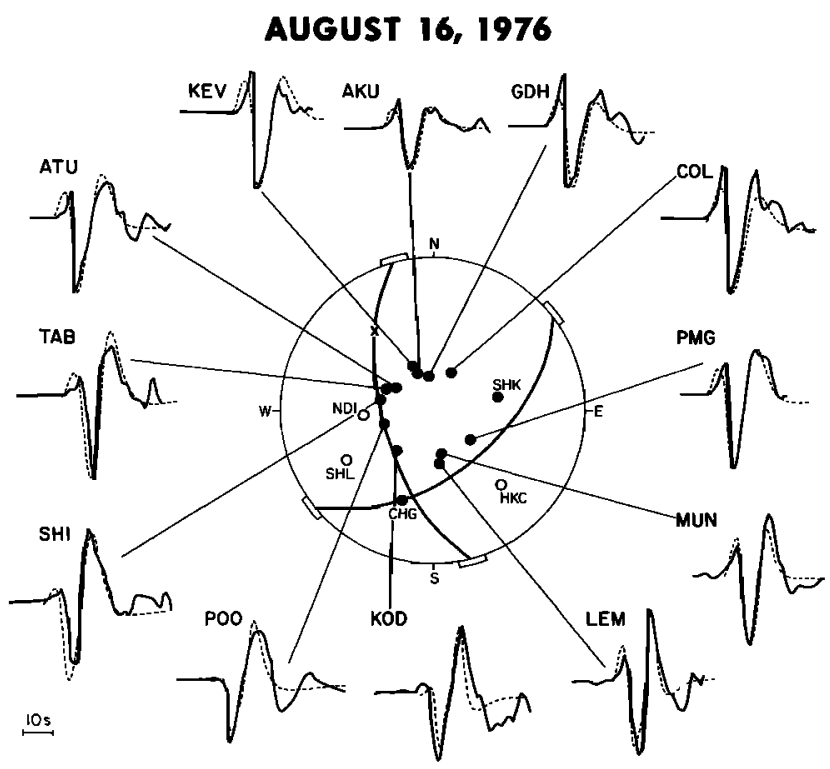

Fig. 5. The fault plane solution determined for the first mainshock (August 16, 1976) of the Songpan sequence. The observed (solid lines) and calculated (dashed lines) waveforms at WWSSN stations used to determine the fault plane solution are shown with the first motions of nearby stations.

depths of the first and third mainshocks are around $10 \mathrm{~km}$, and their aftershocks extend down another 5-10 km. The second mainshock, in contrast, has a hypocenter around $7 \mathrm{~km}$ depth and its aftershocks are all shallower than $10 \mathrm{~km}$. In addition, whatever the depths are, the narrowness of the epicentral distribution for the first and third events shows that these events must have steeply dipping fault planes (probably greater than $60^{\circ}$ ) (Figure 4 ).

\section{Fault Plane Solutions}

Because the distribution of local stations is relatively sparse in China, determination of focal mechanism solutions using local data requires using mostly refracted arrivals. As the velocity structure of China is not well determined, this can lead to significant uncertainties in the solutions. First motions of teleselsmic arrivals were also insuffictent for constraining the focal mechanisms. Waveform modeling of longperiod selsmograms at teleseismic distances has therefore been used to determine the focal mechanisms of the three mainshocks.

The methods used here for modeling the waveforms are described by Chen et a1. [1981]. Synthetic seismograms for 10-12 Wor1d-Wide Standard Selsmograph Network stations were generated using point sources with trapezoidal time functions for various focal mechanisms convolved with an appropriate $Q$ operator, the path function, and instrument response. These synthetic seismograms were matched with the observed traces by trial and error to estimate the appropriate focal mechanisms, source-time functions, and depths of the mainshocks. Stations from $30^{\circ}$ to $90^{\circ}$ distance from the earthquakes were modeled. The velocity model at the source was the same as the one that was used in the aftershock relocations. The attenuation was calculated using an as sumed $t^{*}$ of $1.0 \mathrm{~s}$.

\section{Results}

The best fitting fault plane solution for each of the mainshocks with the calculated and synthetic selsmograms used in the determination are shown in Figs 5-7. The plotted time axes are the same for all of the seismograms. The amplitudes are scaled to match the observed seismogram, and the scaling factor is used to determine the moments. Stations that are too close to the earthquakes $\left(\Delta\left\langle 30^{\circ}\right)\right.$ to allow modeling of their waveforms but whose long-period first motions have been used are also shown. The parameters of the fault plane solutions are included in Table 1 .

August 16, 1976, $M=7.2$. The fault plane solution of the first mainshock is relatively well constrained (Figure 5). The strike of one plane, $165^{\circ} \pm 10^{\circ}$, is subparallel to the distribution of its aftershocks. This plane dips $63^{\circ}$ to the west which, given the uncertainties in our hypocenters, can be reconclled with the aftershock locations. The rake of $40^{\circ}$ shows that the motion on the fault was about half reversetype motion and half left-lateral strike slip. The depth of $12 \mathrm{~km}$ is similar to the depth of approximately $10 \mathrm{~km}$ determined in the hypocentral solutions.

A11 of the source parameters of the solution are relatively we11 constrained. The strike of the main fault plane is the least wel1constrained parameter, but it cannot vary more than $+10^{\circ}$ and still allow both of the stations KOD and SHI to resemble the observed waveforms. The dip of the fault plane must be held within

\section{AUGUST 21, 1976}

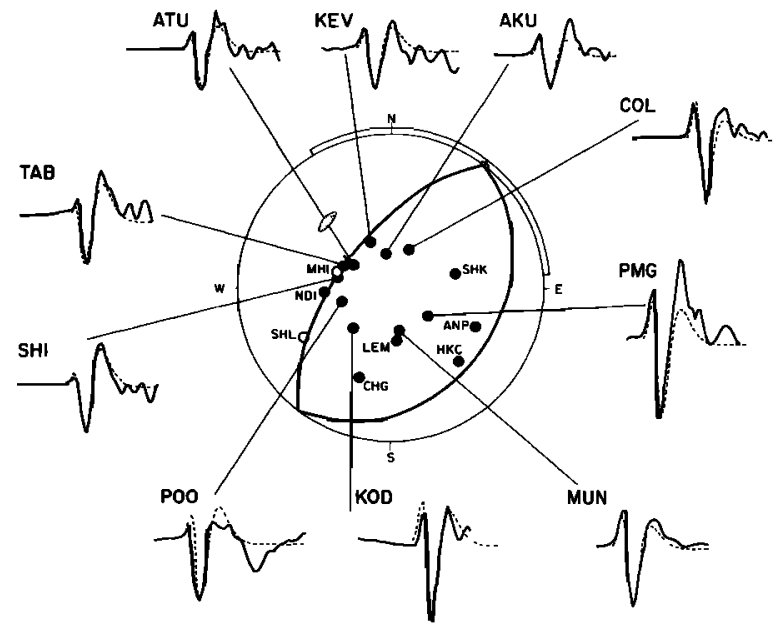

Fig. 6. The fault plane solution determined for the second mainshock (August 21, 1976) of the Songpan sequence. The observed (solid lines) and calculated (dashed lines) waveforms at WWSSN stations used to determine the fault plane solution are shown with the first motions of nearby stations. The location of the slip vector of the first mainshock is shown by the hatched area. The time scale is the same as Figure 5. 
$\pm 2^{\circ}$ of $63^{\circ}$ to maintain the very nodal character of the arrival at P0O. Variations of the rake of more than $\pm 5^{\circ}$ would unacceptably alter the characteristics of the waveforms at PMG (for a shallower rake) or MUN and LEM (for a steeper rake). The depth used is a compromise between the greater depth suggested by the large $s \mathrm{P}$ arrival at $\mathrm{COL}$ and the lesser depth suggested by the small sP at KEV. Any change of more than \pm 2 $\mathrm{km}$ would make one of these waveforms unacceptable.

The time function used for this modeling was trapezoidal with a rise and fall time of $2 \mathrm{~s}$ each and a total duration of $8 \mathrm{~s}$. The average of the seismic moments calculated at each station was Mo $=1.3 \times 10^{19} \mathrm{~N} \mathrm{~m}$. It is interesting to note that there was an azimuthal variation in both the computed moments and the width of the signal. The southwestern stations had larger-amplitude and longer-duration signals than the northeastern stations. The variation was rather large, with a maximum of $M_{0}=2.0 \times 10^{19} \mathrm{~N} \mathrm{~m}$ at LEM and minimum of $M_{0}=5.9 \times 10^{19} \mathrm{~N}$ m at GDH. This phenomenon cannot result solely from a directivity effect since the $M_{0}$ would be the same, and thus the larger amplitudes would be associated with the narrower pulses rather than with the broader pulses seen here [Ben-Menahem, 1961].

August $23,1976, M=7.2$. The fault plane solution of the third mainshock (Figure 7 ) is very similar to that of the first with similar constraints on the parameters. The dip of the main fault plane is slightly steeper, $65^{\circ}$, than that of the first event because of the dilational (rather than nodal compressive arrival, like the first mainshock) arrival at POO. The small second peak at COL suggests a shallower depth, or $8 \mathrm{~km}$ rather than $12 \mathrm{~km}$. The other difference between the first and third mainshocks is that the traces of the third mainshock have a shorter duration than those of the first (the temporal axes in Fig 5-7 are on the same scale). The strike and rake of the third mainshock are the same as those of the first $\left(\mathrm{N} 15^{\circ} \mathrm{W}\right.$ and $40^{\circ}$, respectively).

Although the magnitudes determined by the Sichuan Provincial Seismology Bureau for the first and third mainshocks are the same, the moment calculated for the third event is smaller than that of the first, or $M_{0}=8.4 \times 10^{18} \mathrm{~N} \mathrm{~m}$. The time function is also shorter, or $6 \mathrm{~s}$ total, with $2 \mathrm{~s}$ each for rise, duration, and fall times. This event also shows the azimuthal variation in amplitude and duration seen for the first event.

August $21,1976, M=6.7$. The distribution of first motions and the shape of the recorded waveforms of this mainshock are quite different fron those of the other two (Figure 6), which is not surprising given the large change of strike in the fault at the epicenter of this event seen in the aftershock distributions. The fault plane solution of this event is also less we11 determined than those of the other malnshocks. In fact, most of the constraint on this solution comes from the long-period first motions of stations which are too close to the epicenter $\left(\Delta\left\langle 30^{\circ}\right)\right.$ to allow modeling of their waveforms.

Two dilational first motions tightly constrain one of the focal planes at $35^{\circ}-40^{\circ}$ with a dip of $60^{\circ}$ to the northwest. There are few restrictions on the placement of the second plane. Maintain-

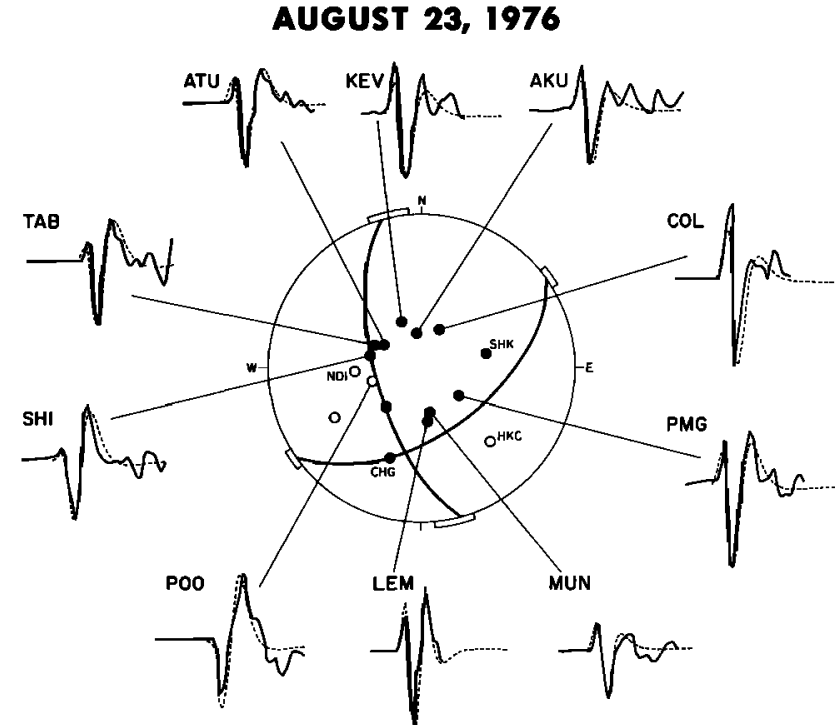

Fig. 7. The fault plane solution determined for the third mainshock (August 23, 1976) of the Songpan sequence. The observed (solid 11nes) and calculated (dashed lines) waveforms at WWSSN stations used to determine the fault plane solution are shown with the first motions of nearby stations. The time scale is the same as Figure 5.

ing the first motions seen at the nearby stations (SHK, HKC, and ANP) requires the rake to be between $70^{\circ}$ and $130^{\circ}$, but none of the modeled stations are sensitive to variations in the rake. The synthetic waveforms match the observed traces well at all stations except PMG and AKU. However, the only way to fit the data from these stations is to reduce their direct $P$ arrivals by bringing them closer to a focal plane, which is impossible while maintaining the first arrivals at the near stations.

The we11-constrained plane is probably the actual rupture plane. While both planes could strike $N 35^{\circ} \mathrm{E}$ parallel to the aftershock zone, the unconstrained plane would have to have a very shallow dip to strike in this directlon. The hypocentral distribution of the aftershocks is not well enough constrained to determine the direction of the dip of the rupture surface, but the narrow distribution of the epicenters does show that the dip must be steep.

While the waveforms are not sensitive to the allowed changes in the focal mechanism, they are sensitive to changes in depth. It is clear that the second event is shallower than the other two mainshocks. A depth of $5 \mathrm{~km}$ and a duration of 6 $s$ (2 s each for rise, duration, and fall times) are used in the modeling presented here. The moment of this event is one third that of the first mainshock or $M_{0}=4.0 \times 10^{18} \mathrm{~N}$ m.

The seismic moment determined here by the amplitudes of the $P$ wave arrivals is equivalent [Aki and Richards, 1980] to that determined from field evidence by

$$
M_{0}=\mu \quad \mathbf{u}
$$

where $\mu$ is the elastic modulus, $u$ is the average slip on the fault, and $A$ is the area of the 
TABLE 1. Source Parameters of the Mainshocks

\begin{tabular}{|c|c|c|c|}
\hline & \multicolumn{3}{|c|}{ Mainshock } \\
\hline & August 16 & August 22 & August 23 \\
\hline Magnitude & 7.2 & 6.7 & 7.2 \\
\hline $\begin{array}{l}\text { Latitude, N } \\
\text { Longitude, } \mathrm{E}\end{array}$ & $\begin{array}{r}32.722^{\circ} \\
104.092^{\circ}\end{array}$ & $\begin{array}{r}32.612^{\circ} \\
104.151^{\circ}\end{array}$ & $\begin{array}{r}32.475^{\circ} \\
104.095^{\circ}\end{array}$ \\
\hline $\begin{array}{l}\text { Longitude, } \mathrm{E} \\
\text { Depth, }{ }^{\mathrm{a}} \mathrm{km}\end{array}$ & $\begin{array}{c}104.092^{\circ} \\
8.5\end{array}$ & $\begin{array}{c}104.151 \\
5.5\end{array}$ & $\begin{array}{c}104.095^{\circ} \\
9.5\end{array}$ \\
\hline Length, ${ }^{a} \mathrm{~km}$ & 30 & 12 & 22 \\
\hline Strike, deg & 165 & 215 & 165 \\
\hline Dip, deg & 63 & 60 & 65 \\
\hline Rake, deg & 40 & 90 & 40 \\
\hline Depth, ${ }^{b} \mathrm{~km}$ & 12 & 5 & 8 \\
\hline Source time, & 8 & 6 & 6 \\
\hline$M_{0} \times 10^{18}, N_{m}$ & 13.0 & 4.0 & 8.4 \\
\hline WIdth, ${ }^{c} \mathrm{~km}$ & 12 & 8 & 11 \\
\hline slip, m & 1.1 & 1.2 & 1.1 \\
\hline
\end{tabular}

a From HYPOINVERSE locations.

b From waveform modeling.

c Estimated from average of depths $a$ and $b$ and width of fault.

fault. Thus the moment determined here can be used with the estimates of the faults' length and width from the aftershock distributions (Table 1) and an assumed of 33. GPa to estimate the slip on the faults during the earthquakes. The estimates for all three of the mainshocks are approximately the same (Table 1), or $1.1 \mathrm{~m}$. This results from the fact that although the moments vary by a factor of 3 between the mainshocks, the lengths of the aftershock zones also vary by about the same amounts. Because of the 1naccessibility of the epicentral area, no field measurements of surface rupture were made with which these estimates could be compared.

Precursory Swarm

$\underline{\text { Data }}$

The precursory swarm started with a $M=5.2$ event in May 1973 and continued until the occurrence of the Songpan mainshocks. The temporal development of the swarm is shown in Figure 8 . The highest level of activity was in August 1973 when an event of $M=6.2$ occurred. The level of activity decreased noticeably in 1974 and then rose again moderately in 1975 and 1976. Al1 of the events with $M \geq 3.5$ in 1973 and 1974 and all of the events with $M>3.0$ in 1975 and 1976 were relocated for this study. The station network avallable for locating these events is somewhat smaller than that used for the aftershocks. In Figure 2 the eight stations shown by solid triangles were in operation throughout the swarm, and those shown by open triangles began operation in the summer of 1974. The open circles were not in operation until just before the mainshocks.

\section{Resu1ts}

The epicenters of the swarm events are shown with those of the aftershocks of the Songpan mainshocks in Figure 9. The southern edge of the swarm area abuts the initial rupture area of the first mainshock seen in the first 3 hours (see Figure 4a). The later northward extension of the aftershock zone of the first mainshock lies along the eastern edge of the area involved. In the swarm.

The swarm appears to occur over a volume rather than on a planar feature like the aftershocks in the same area. Because the quality of the locations of the events in the swarm is not as high as those of the aftershocks, we checked this observation by comparing the S-P times of the swarm events and the aftershocks at a station, Songpan ( 1 in Figure 2), that 11es almost due west of the events. Since the Huya fault runs approximately north-south, an eastwest distribution of events (such as appears to be true of the swarm events) should cause a wider distribution of S-P times at Songpan than a north-south distribution (like that shown by the aftershocks) would. A much wider distribution of S-P times at Songpan is indeed seen for the events within the swarm than for the aftershocks (Figure 10). Moreover, it is quite clear that the events in the swarm did not occur in the same place as the aftershocks.

\section{Discussion}

The aftershock locations and fault plane solutions presented above allow us to determine considerable detail of the rupture process of this earthquake triplet. The first and third mainshocks occured on parallel strands of the fault with almost identical senses of motion, a combination of left-lateral strike-slip and reverse motions. These two strands are separated by a right-stepping en echelon offset in the fault. Through this offset, another fault on which the second mainshock occurred is observed at an angle of $120^{\circ}$ to the other fault strands. Each of the mainshocks appears to have ruptured only one of the strands of the fault. A schematic of this geometrical relation is shown in Figure 11 .

The sense of the motion during the second mainshock is not uniquely determined from the fault plane solutions and aftershock locations alone. However, the relative geometry of the

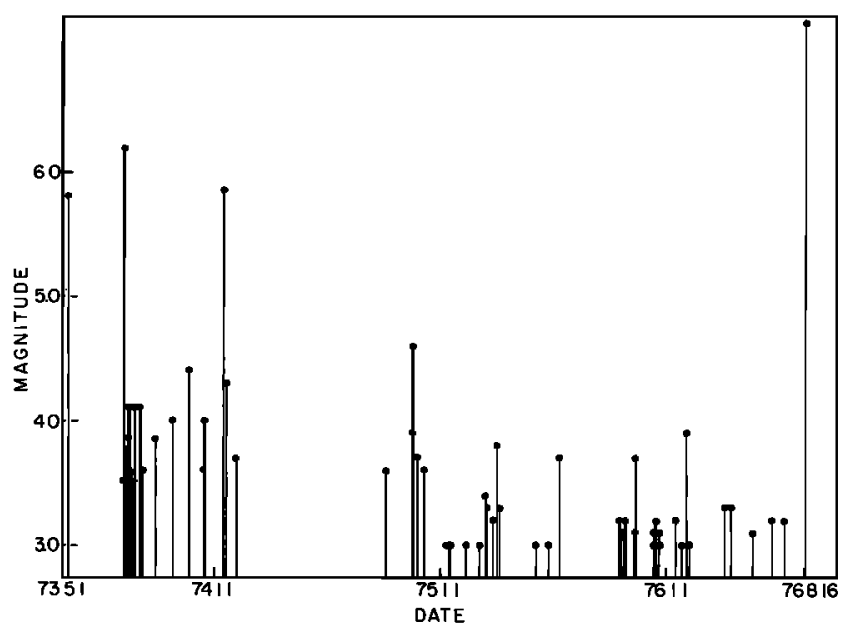

Fig. 8. A plot of magnitude versus time for the events in the precursory swarm located in this study. 
fault strands can provide some limitation on the possible sense of motion during the second mainshock. The slip vectors determined in the fault plane solutions show the direction of relative motion of the material on either side of each fault. Because the faults are adjacent to each other, the same blocks of material are moving in each mainshock. As the amount of slip in each event was the same, any change in slip vector between the events will require volumetric deformation within the fault blocks.

The location of the slip vectors of the first and third mainshocks is shown on the fault plane solution of the second mainshock in Figure 6 . One should note that the rupture plane of the second mainshock dips too steeply to allow the difference in the slip vectors to be completely eliminated. Hence some internal deformation in the blocks must have taken place. However, because the amount of slip in each mainshock was the same and all of the earthquakes occurred on the boundary of the same block, suggesting block motion, we consider the fault plane solution that minimizes the differences between slip vectors as the most likely solution. This is the pure reverse motion solution shown in Fig 6 .

This misalignment of slip vectors might also be related to a change in stress between the mainshocks. The slip during the first event would have increased the shear stress for pure reverse motion on a more shallowly dipping fault. Because the fault actually dipped more steeply, the stress change on that fault included an increase in the normal stress. This increase could have delayed the rupture of the second strand, resulting in the five day interval between the two events. In contrast, the misalignment of slip vectors between the second and third mainshocks would have decreased the normal stress on the fault strand of the third event. The delay between these two events was only 30 hours. Overall, the fault misalignment may have caused this sequence to be a triplet of earthquakes rather than a multiple rupture.

Scholz [1982] presented data that suggested

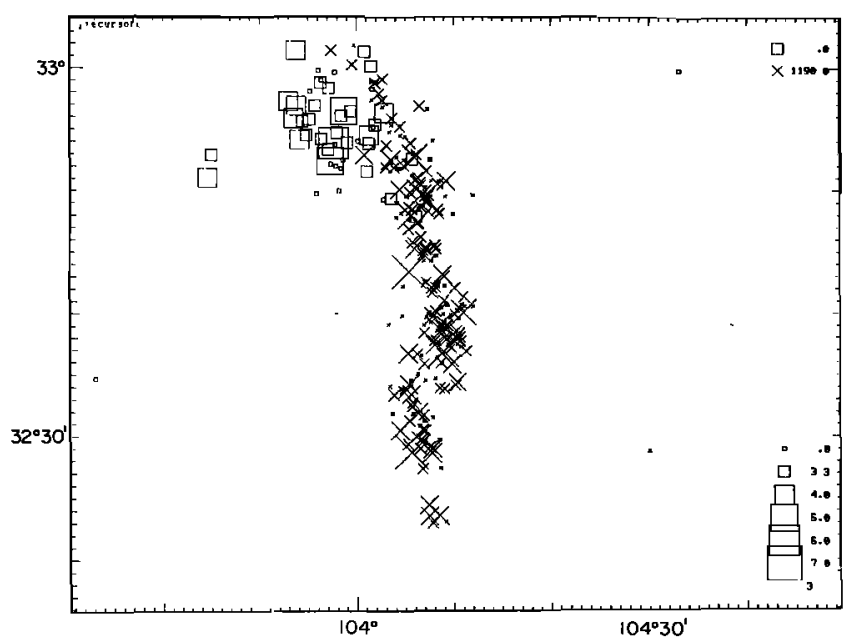

Fig. 9. The locations of the events in the precursory swarm and the aftershocks of 1976 mainshocks. The events in the swarm are shown by squares and the aftershocks by crosses.

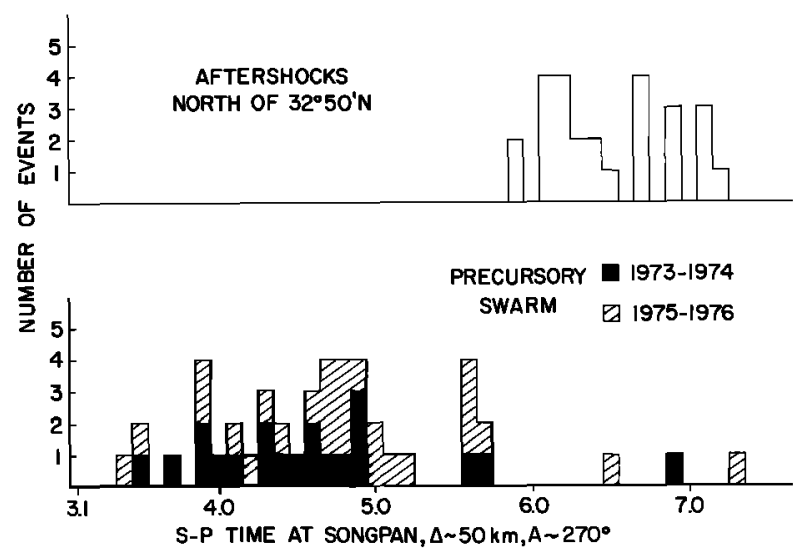

Fig. 10. The number of events with given S-P $t$ imes recorded at Songpan station (1 in Figure 2)

for both the events in the precursory swarm and the northernmost aftershocks.

that for most earthquakes the slip is proportional to the length of the fault. The first mainshock of this sequence has been shown to have a slip-length ratio in proportion to those of many major Chinese earthquakes [Molnar and Deng, 1984]. However, this proportionality obviously does not hold for all three mainshocks since the lengths determined from aftershock locations vary by a factor of 3 but the slip is the same. This would suggest that the second mainshock had a higher stress drop than the other mainshocks. This idea is supported by the higher ratio of source function to moment of the second event compared to the other two (Table 1).

Several aspects of the precursory swarm suggest that it is related to the occurrence of the Songpan earthquake sequence. F1rst, the time between the start of the swarm and the mainshocks ( 1200 days) is the same as that seen for precursory swarms to earthquakes of this size in Soviet Central Asia [Kristy and Simpson, 1980]. The magnitude $(6.2)$ of the largest event in the swarm is also the same as that predicted for a $M$ $=7.2$ mainshock from the same Soviet data. Second, the earthquakes in the swarm had been occurring for 3 years and then ceased after the occurrence of the Songpan earthquakes. Third, the original rupture area of the first mainshock (seen in the first 3 hours of aftershock activity, Figure 4a) terminates at the start of the volume occupied by the swarm. It is the northernmost section of the aftershock zone that formed well after the initial rupture that runs as a planar feature along the edge of the swarm volume. This area of overlapping swarm and aftershock activities is located beyond the end of the mapped Huya fault. This could suggest that the swarm and gradual extension of the aftershock zone represent growth of the fault, perhaps as part of the extension of the Kunlun fault suggested by Han and Xia [1980]. A similar cause has been suggested for swarms around the Nurek Resevoir in Soviet Central Asla [Leith et a1., 1980]. Such a hypothesis, however, requires further evidence, especially geologic mapping, to be proven. In other cases, swarms have been seen at the ends of future aftershock zones where 


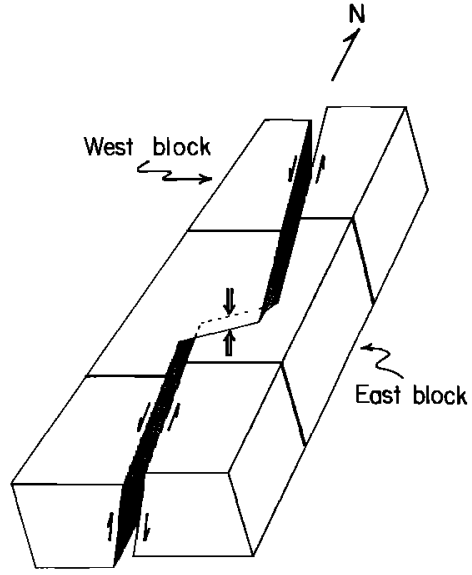

Fig. 11. A schematic of the proposed block motion and geometrical relationship between the different strands of the Huya fault.

there is no evidence of growing faults [Johnson and Hil1, 1983].

\section{Conclusions}

Using local and teleselsmic data, the aftershock distributions and focal mechanisms of the Songpan triplet of earthquakes have been determined. The earthquakes occurred on a complex fault, composed of two parallel strands, separated by a large en echelon offset through which another fault strand has formed at a $120^{\circ}$ angle to the other strands. Each of the three mainshocks occurred on a different strand of the fault, from north to south with abutting rather than overlapping aftershock zones. The first and third mainshocks showed a combination of reverse and left-lateral strike-slip motion. The motion of the second mainshock is not as well constrained, but geometrical considerations suggest that most of the motion was reverse. Such shortening is consistent with the right-stepping of fset in the left-lateral Huya fault.

Acknowledgments. This research was conducted under the auspices of the protocol for scientific exchange between the State Seismology Bureau (SSB) (of the People's Republich of China) and the U.S. Geological Survey (USGS) (of the United States of America). The research was supported by the USGS under Earthquake Hazard Reduction Act contract USGS 1408000120620 and by the SSB. We would like to thank the Institute of Geophysics of the SSB for their hospitality in Beijing and especially $\mathrm{Xu}$ Shaoxie for his help in arranging this project. We would also like to thank the Sichuan Provincial Selsmology Bureau, expecially Li Xinghai and Hong Xlangming, for their support and hospitality during the 2 months of work in Chengdu. We also thank Bill Bakun for supplying us with the HP-85 computer for use in Chengdu and Gerardo Suarez for supplying advice, help, and programs for the synthetic seismograms. Mary Ann Luckman and Kazuko Nagao drafted the figures. Paul Richards and David Simpson critically reviewed the manuscript. Lamont-Doherty Contribution Number 3669.

\section{References}

Aki, K., Characterization of barriers on an earthquake fault, J. Geophys. Res., 84, 6140$6148,1979$.

Aki, K., and P. G. Richards, Quantitative Seismology; Theory and Methods, W. H. Freeman, San Francisco, Calif., 1980.

Ben-Menahem, A., Radiation of seismic surface waves from finite moving sources, Bull. Seismo1. Soc. Am., 51, 401-435, 1961.

Chen, W. P., J. Nabalek, T. J. Fitch, and P. Molnar, An Intermediate depth earthquake beneath Tibet: Source characteristics of the event of September 14, 1976, J. Geophys Res., 86, 2863-2877, 1981 .

Das, S., and C. H. Scholz, Theory of timedependent rupture in the earth, J. Geophys. Res., 86, 6039-6051, 1981.

Evison, F. F., Fluctuations of seismicity before major earthquakes, Nature, 266, 710-712, 1977a.

Evison, F. F., The precursory earthquake swarm, Phys. Earth P1anet Inter., 15, 19-23, $1977 \mathrm{~b}$.

Feng, C., and T. Teng, Three-dimensional crust and upper mantle structure of the Eurasian continent, J. Geophys. Res., 88, 2261-2272, 1983.

Fukao, Y., and M. Furumoto, Foreshocks and multiple shocks of large earthquakes, Phys. Earth Planet Inter., 10, 355-368, 1975.

Han, W., and D. Xia, The Songpan-Pingws earthquakes and the movement of the Sichuan-Qinghal block, (In Chinese) Earthquake Sci. Res., 1, $39-48,1980$.

Jennings, P. C., (Ed.), Earthquake Engineering and Hazards Reduction in China, CSCPRC Rep. 8, 189 pp., National Academy of Sciences, Washington D. C., 1980.

Johnson, C. E., and D. P. Hill, Seismicity of the Imperial Valley, in The Imperial Valley, California, Earthquake of October 15, 1979 , Edited by C. Johnson, C. Rojahn, and R. Sharp, U.S. Geol. Surv. Prof. Pap., 1243,15-24, 1984.

Jones, L. M., B. Wang, S. Xu, and T. Fitch, The foreshocks sequence of the February 4, 1975 Halcheng earthquake $(M=7.3)$, J. Geophys. Res., 4574-4584, 1982.

Kanamori, H., and G. S. Stewart, Seismological aspects of the Guatemala earthquake of February 4, 1976, J. Geophys. Res., 83, 3427-3435, 1978.

Klein, F. W., Hypocenter location program HYPOINVERSE, part 1; Users guide to versions 1 , 2, 3, and 4; part 2; Source listings and notes, U.S. Geo1. Surv. Open File Rep. 78-694, 114 pp., 1978.

Kristy, M. J., and D. W. Simpson, Seismicity changes preceding two recent Central Asian earthquakes, J. Geophys. Res., 85, 4829-4837, 1980.

Leith, W., D. W. Simpson, and W. Alvarez, Structure and permeability; Geologic control on induced seismicity at Nurek Reservolr, Tadjikistan, USSR, Geology, 9, 440-449, 1981.

Mogi, K., Relationship between the occurrence of great earthquakes and tectonic structure, Bull. Earthquake Res. Inst.Tokyo Univ., 47, 429-451, 1969. 
Molnar, P., and Q. Deng, Faulting associated with large earthquakes and the average rate of deformation in central and eastern Asia, J. Geophys. Res., 6203-6227, 1984.

Rial, J. A., The Caracas, Venezuela, earthquake of 1967: A multiple-source event, J. Geophys. Res., 83, 5405-5414, 1976.

Scholz, C. H., Scaling laws for large earthquakes: Consequences for physical models, Bull. Selsmol. Soc. Am., 72, 1-14, 1982.

Sichuan Provincial Seismology Bureau, The 1976 Songpan Earthquakes, (in Chinese), Seismology Press, Belj1ng, 1979 .

Sichuan Provinclal Selsmology Bureau, Compilation of Data on Earthquakes in Sichuan, (in Chinese)., 2 vo1., Before 1949, 576 pp., After 1949, 224 pp., Sichuan People's Press, Chengdu, Sichuan, 1980 .

Tapponier, P., and P. Molnar, Active faulting and tectonics of China, J. Geophys. Res., 82, 2905$2930,1977$.

Wallace, R. E., and T. Teng, Prediction of the Songpan-Pingwu earthquakes of August 1976, Bul1. Se1smol. Soc. Am., 70, 1199-1233, 1980.
Wesnousky, S. G., L. M. Jones, Q. Deng, and C. H. Scholz, Historical seismicity and crustal deformation along the Ordos block, northeast China, in press, Bull. Seismol. Soc. Amer., 1984.

W. Han, Y. Zhang, and Z. Luo, Sichuan Provincia1 Seismology Bureau, Chengdu, Sichuan, People's Republic of China.

E. Hauksson, Department of Geological Sciences, University of Southern California, Los Angeles, CA 90089-0741

A. Jin, Institute of Geophysics, State Seismology Bureau, Beij1ng, People's Republic of China.

L. M. Jones, U.S. Geological Survey, Earthquakes, Volcanoes, and Engineering, Seismological Laboratory 252-21, California Institute of Technology, Pasadena, CA 91125

(Received September 13, 1983;

revised March 5, 1984;

accepted March 30, 1984). 